\title{
El duelo educativo y el rediseño como desafío de superación
}

\section{Educational mourning and redesigning for overcoming challenge Luto e redesenho educacional como um desafio de superação}

\author{
Leonel Ángel Carlini López \\ Universidad Tecnológica Nacional \\ Buenos Aires, Argentina \\ psicopedagogocarlini@gmail.com
}

Recibido - Received - Recebido: 15 / 07 / 2020 Aceptado - Accepted - Aprovado: 14 / 08 / 2020

DOI: https://doi.org/10.22458/ie.v22iespecial.3157

URL: https://revistas.uned.ac.cr/index.php/innovaciones/article/view/3157

\begin{abstract}
Resumen: La pérdida de los tradicionales formatos educativos superiores impulsó el rediseño de la tríada didáctica lanzada a la virtualidad. Esta ruptura obligada configuró al aula virtual como una legalidad democratizadora. Los docentes que emprendieron el desafío de recuperar la pulsión epistemofílica, quienes humanizaron las pantallas, ampliaron los límites de su capacidad simbólica.
\end{abstract}

Palabras clave: Rediseño; Aula virtual democratizador; Pulsión epistemofílica

\begin{abstract}
The loss of the traditional higher education arrangements prompted the redesigning of the didactic triad and has launched it into virtuality. This forced rupture has rearranged the virtual classroom as a democratizing legality. The teachers who undertook the challenge of recovering the epistemophilic drive, humanized the screens, and expanded the limits of their symbolic capacity.
\end{abstract}

Key Words: redesigning, democratizing virtual classrooms, epistemophilic drive, COVID-19

Resumo: A perda dos formatos tradicionais do ensino superior impulsionou o redesenho da tríade didática lançada na virtualidade. Esta ruptura forçada configurou a sala de aula virtual como uma legalidade democratizadora. Os professores que assumiram o desafio de recuperar a pulsão epistemofílica, que humanizaram as telas, ampliaram os limites de sua capacidade simbólica.

Palavras-chave: Redesenho, democratização da sala de aula virtual, pulsão epistemofílica, COVID-19

\section{INTRODUCCIÓN}

La pandemia por el virus responsable de la COVID-19 irrumpe en nuestras vidas al modo de un cataclismo. Repentina, invasiva, inesperada, cambia las rutinas de nuestros modos de habitar el mundo. Impacta en nuestro ser, obliga a que adoptemos nuevas formas de sostener actividades básicas como alimentarnos, estudiar y trabajar. De pronto, todo lo cercano puede resultar una amenaza, en términos de contraer un virus desconocido, en términos de perder la vida.

Ante fuertes catástrofes, desastres naturales o accidentes imprevistos, el psiquismo de un sujeto dispone toda su energía en sobreponerse a lo repentino, sin poder focalizar en otras actividades en ese momento, aunque sean rutinarias o habituales. Algo de lo propio ocurre con el advenimiento del coronavirus a nuestras cotidianeidades; entonces, sostener y metabolizar el confinamiento se convierte en la actividad central de nuestro pensamiento. 
La universidad no queda exenta de esa interpelación. La COVID-19 pone al descubierto los recursos simbólicos con los que cuentan tanto estudiantes y docentes a la hora de la llegada del confinamiento. En este sentido, los centros de formación superior tienen que sobreponerse con velocidad inusitada y empezar a diseñar nuevos dispositivos que, sumados a las acciones didácticas y a nuevas estrategias pedagógicas para atender el contexto de emergencia sanitaria en que entraron los países, garantizan el sostenimiento de la regularidad de las carreras. Es así que un virus muestra los entretelones que existen al interior de las aulas. Se hallan, en gran número, universidades sin plataformas webs, docentes analfabetos digitales, según dice desde hace tres años Ricardo Slavutsku, decano de la Facultad de Humanidades y Ciencias Sociales de la UNJU y estudiantes con dificultades en la conectividad. El Sistema Superior se encuentra desnudo, debiéndose de-construirse en cuestión de días.

Ante este nuevo escenario, los aprendizajes que se presentan son múltiples, pero todos ponen en jaque saberes anteriores. Ahora la clase ya no se planifica con idéntica lógica y, consecuentemente, los estudiantes se encuentran con nuevos formatos educativos que deben ser interpretados con el fin de adquirir competencias profesionales y dar continuidad al proceso de formación académica.

Estas irrupciones, producto de la pandemia global, dejan como resultante saberes insoslayables para la planificación de las carreras de aquí en adelante, tal es así que algunos claustros de formación por estos días evalúan dar continuidad a la modalidad "on line". En este escenario, surgen muchos interrogantes sobre las modalidades de respuestas con las que los institutos de formación profesional garantizan la acreditación de las competencias de ahora en más.

\section{EL AULA VIRTUAL, UN NO LUGAR}

El aula virtual, el nuevo escenario para aprender, se configura como resultado de la intersección de dos nóveles espacios: la vivienda del docente y la vivienda del estudiante. Este lugar denominado "aula virtual", deja de ser un salón de clases real, concreto, palpable, para convertirse en un clic, un simple enlace en la lectura de algún archivo en formato PDF, una visualización de YouTube o la observación de una sesión de oratoria con pocas posibilidades de interacción. Es importante considerar que no en todos los contextos la educación superior se virtualizó, por cuanto, en muchos casos, a lo que se recurrió fue al traslado de la presencialidad tradicional a una educación apoyada en recursos digitales, lo que en otros contextos denominan "presencialidad remota".

Oportunamente la virtualidad empieza a operar como un elemento democratizador de la formación superior, en tanto que las reglas de juego ya no son puestas por el profesor en la privacidad del Aula Magna, sino que los mecanismos de asimetría pedagógica ahora se expresaban en plataformas a las que podían acceder -en igual medida- tanto estudiantes como directores de carrera. Advino un sutil detalle de ingresos, intervenciones, producciones de estudiantes y docentes, las cuales se configuraron en huellas digitales, delineando en cada elección un camino, una trayectoria en la que se construye subjetividad, porque supone un sujeto que se autoriza a participar, decidir, hacer.

Este no lugar virtual, sin espacio, echa por tierra la privacidad de las cuatro paredes -muchas veces compatible con la impunidad- para introducir luz a un "no lugar" compartido con otros, en donde la audiencia se amplía y, consecuentemente, se democratiza. Esto último puede resultar aterrador para quienes resisten los cambios todavía, añorando un tiempo pasado.

La virtualidad opera en tanto terceridad, dado que rompe con la estructura dialógica del aula presencial, ubicándose en un recorrido visible para muchos. De esa manera, ya no es lo que dice el estudiante o lo que plantea el docente, es ciertamente lo que está descrito en ese no lugar, al que también asisten otros actores institucionales. En ese sentido, la terceridad democratiza porque erradica en gran medida la posibilidad de un ejercicio del poder del profesor por sobre el cuerpo del aprendiz en términos de no poder requerir su presencia física en el aula. Si bien esto, no es extinguible por completo, lo que se instaló es la disminución de la ocurrencia de estos ejercicios asimétricos perversos. 


\section{TRÍADA POSPANDEMIA}

Si bien es sabido que la escuela enciclopedista en Latinoamérica deja resabios que todavía persisten y se hacen carne en prácticas de educadores actuales, estas estrategias didácticas de antaño se hacen añicos ante la llegada del virus responsable de la COVID-19.

El coronavirus impulsa el despliegue de la capacidad de representación de la tríada (educador- aprendizconocimiento). Este triángulo también sufre efectos ante el confinamiento. Los últimos meses muestran un docente que no se erige como el portador del conocimiento, sino que se refleja en su rol que se trata de un mediador, de un catalizador que oferta novedades despertando la curiosidad a partir del interés, el sentido y el afecto. La repetición de definiciones deja de ser una estrategia cognitiva en la educación a distancia, pierde su sentido ante la existencia de los buscadores de internet.

Las estrategias memorísticas dejan lugar a los argumentos producto de la lectura del material, la visualización de recursos audiovisuales y las conclusiones de los foros de discusión. Se habilita nada menos que la posibilidad de que cada estudiante sea capaz de construir cultura, encontrándose frente al conocimiento, interpelándolo, poniendo su impronta para finalmente recrear su mundo interior. Vale aclarar también, que en muchos casos, la clase magistral migra de espacio, de la presencialidad al recurso digital, por lo tanto persisten situaciones tradicionales en medios innovadores o digitales, que aunque son los mínimos se mantienen.

El padre del psicoanálisis, Sigmund Freud (1900), cuando describe la pulsión epistemofílica o de conocer, plantea que para que un sujeto aprenda se le debe ofertar una novedad dejando lugar a que otras informaciones sean develadas, algo que es mostrado y algo está oculto, que se debe descubrir. De este modo opera, en el aprendizaje, una función psíquica esencial de las personas. Vale recordar que la pulsión de saber va de la mano del concepto de sublimación (Laplanche y Pontalis,1967, p. 415).

La novedad, esencial para construir nóveles aprendizajes, se convierte en uno de los desafíos centrales que tienen los educadores frente al coronavirus. ¿Cómo lograr despertar la curiosidad con los recursos tecnopedagógicos con que se cuenta, cómo ofertar algo novedoso dejando algo pendiente por develar en un aula virtual, en un espacio no real? El desafío se hace titánico en la mayoría de los casos y supone un duelo en cada uno de los actores educativos. Aceptar que la realidad ha cambiado, que los recursos son intangibles, que el espacio no es corpóreo. Aceptarlo es la tarea que sobreviene luego de sobreponerse a lo traumático que representa para muchos el confinamiento. Quienes aceptaron, pueden reinventarse ampliando los límites de su capacidad simbólica.

\section{REFERENCIAS}

Aebli, H. (1951). La didáctica tradicional y su fundamento psicológico. En H. Aebli (Ed.), Una didáctica fundada en la psicología de Jean Piaget. Buenos Aires: Editorial Kapelusz.

Bruner, J. (1969). El desarrollo de los procesos de representación. En J. Linaza (Ed.), Acción, pensamiento y lenguaje. Madrid: Alianza.

Chevallard, Y. (1991). La transposición didáctica: del saber sabio al saber enseñado. Aique: Buenos Aires.

Freud, S. (1915). Las pulsiones y los destinos de la pulsión. En J. Strachey (Ed.). Obras completas. Buenos Aires: Amorrortu Editores.

Linaza, J. (2003) Cambios en la concepción de educación. En F. Laporta (Ed.), La enseñanza del derecho. Madrid: Universidad Autónoma de Madrid.

PortalTodoJujuy(22demarzode2017).Muchosdocentessonanalfabetosdigitales. Todojujuy. Recuperado de https://www.todojujuy.com/jujuy/muchos-docentes-son-analfabetos-digitales-n58737 